\title{
TITLE:
}

\section{Coarse graining of wood cell arrangement and density dependence of elasticity}

$\operatorname{AUTHOR}(\mathrm{S})$ :

Nakano, Takato

CITATION:

Nakano, Takato. Coarse graining of wood cell arrangement and density dependence of elasticity. Holzforschung 2013, 67(1): 67-73

\section{ISSUE DATE:}

2013-01-01

URL:

http://hdl.handle.net/2433/187266

\section{RIGHT:}

Copyright of Holzforschung: International Journal of the Biology, Chemistry, Physics, \& Technology of Wood is the property of De Gruyter and its content may not be copied or emailed to multiple sites or posted to a listserv without the copyright holder's express written permission. However, users may print, download, or email articles for individual use. 


\section{Coarse graining of wood cell arrangement and density dependence of elasticity}

\author{
Takato Nakano* \\ Laboratory of Biomaterials Design, Division of Forest \\ and Biomaterials Science, Graduate School of Agriculture, \\ Kyoto University, Kyoto, Japan \\ * Corresponding author. \\ Laboratory of Biomaterials Design, \\ Division of Forest and Biomaterials Science, \\ Graduate School of Agriculture, Kyoto University, \\ Kita-Shirakawa, Kyoto 606-8502, Japan \\ Phone: +81-75-753-6234 \\ E-mail: tnakano@kais.kyoto-u.ac.jp
}

\begin{abstract}
Elastic moduli in each direction have been formulated based on a cell wall model considering a high-order structure of wood. Parameters in the equations are confirmed by comparison to best-fit experimental data, and simulation validates the model presented. The relationship between the logarithmic plots "elastic modulus vs. wood density" is linear in each direction for many wood species and the intercept in the derived equations is constant. The variations within a limited region can be neglected, i.e., they can be coarse-grained. The following parameters were considered: elastic modulus of the cell wall, the fraction of latewood in the transverse section, the density ratio of latewood to earlywood, and the ratio of radial length to tangential length.
\end{abstract}

Keywords: cell model; coarse graining; elasticity; linearity; wood structure.

\section{Introduction}

Wood is an anisotropic porous biomaterial, which consists of various cell types. The sorption, swelling, and mechanical properties depend on the cell arrangements, cell structure, and the supramolecular architecture of the cell wall consisting of cellulose, hemicelluloses, and lignin. The wood cell wall consists of primary and secondary walls, the latter forming three layers. Their layers consist of frameworks and matrices (Fengel and Wegener 1989). The topic has been revisited several times since the review of Kollmann and Coté (1968) from the physical point of view. Salmén and Burgert (2009) reviewed the recent literature on the mechanical properties related to cell wall features, and Stevanic and Salmén (2009) described the state of the art concerning the composition and orientation of wood polymers in the cell wall. The arrangement of cells differs in radial (R), tangential (T), and longitudinal (L) directions. Thus, the elasticity of wood is affected by cellular arrangement, cell wall structure, layer structure, and wood components. Nakano (2003, 2008) analyzed cell wall swelling based on a cylindrical model that considers a partial molecular volume of water adsorption. Taguchi et al. $(2010,2011)$ observed by confocal laser-scanning microscope the anisotropic swelling process of tracheid cells during water adsorption. Concerning anisotropy, the macrostructure of earlywood (EW) and latewood (LW) are also influential. It is generally accepted that the relationship between the elastic modulus $(E)$ and wood density is linear, although the abovementioned structural factors may differ.

Elasticity in the L direction has been analyzed in detail. There are many reports on the effects of a microfibril angle (MFA) on L-elasticity, which is an important factor to consider (Tang and Hsu 1973; Watanabe et al. 1999, 2000, 2002; Salmén 2004; Yamamoto 2004). L-elasticity is related only to the substance ratio and not to the shape of the transverse section.

Transverse elasticity is influenced by cell shape and cell arrangement, and this was analyzed by means of various cell models. Price (1929) introduced a circular section model to this purpose, whereas Houwink (1954) preferred a rectangular section model. Tang and Hsu (1973) derived the $E$ in the R direction based on the rectangular model following the suggestions of Chou and Carleone (1972). They also discussed various previous trials of model analysis in their study. Gibson and Ashby (1999) reviewed $E$ of cell models of various cellular solids.

Previous studies have seldom considered the shape dispersion or cell variety as did Kanaya and Yamada (1964) in their tangential cell model. Maekawa et al. (1993), Watanabe et al. (1999), Watanabe and Norimoto (2000), and Watanabe et al. (2002) evaluated cell wall arrangement by applying a 2D Fourier transform method and confirmed the best-fitting shape parameters. The quoted authors calculated $E$ based on parameters that were in agreement with experimental results.

Ohgama and Yamada $(1971,1974)$ discussed the elasticity of wood from a different viewpoint as quoted above and applied a law of mixtures considering shape factors and found that cell arrangement in each direction is regular for $\mathrm{R}$ shapes (shape factor of 1.1) and zigzag pattern for $\mathrm{T}$ shapes (shape factor of 1.5).

It is generally accepted that the relationship between the elastic modulus and wood density is linear on a logarithmic scale in each direction. This relationship is unexpected because of the different cell wall features of different wood species. Supposedly, different wood species must have some common characteristics, and this can be summarized in the statement that wood is "coarse-grained".

Common characteristics of wood species have been evaluated in the literature in association with elasticity. For example, Hofstetter et al. $(2005,2008)$ analyzed the mechanical properties of wood considering its hierarchical organization, and the derived data were in agreement with those in the literature. 
The shape of wood cells was seldom taken into account in this type of studies. This is the reason why in the present study wood cells will be modeled with various shape parameters. The goal was to examine the validity of the model based on a best-fitting simulation. The linearity between the elastic modulus and wood density on a logarithmic scale will be revisited. The "coarse-grained" nature of wood will also be examined again based on a larger data material than previously used.

\section{Methods and simulation data}

In this study, the model shown in Figure 1a-c is proposed with four parameters $k_{1}, k_{2}, k_{3}$, and $k_{p}$. Cell wall thickness in the model is constant for EW and LW. The elastic moduli in R and T directions were derived by differentiating between EW and LW (Figure 1). Model parameters were established based on T-dimensions and the thickness of EW. This model was then applied to both softwood and hardwood.

Model parameters were determined under best-fitting conditions for 30 wood species. The data are listed in the Forest Industry Wood Handbook (For. and For. Prod. Res. Inst., 1982) and are listed in Table 1. A commercial application software (Microsoft Excel Solver) was used for simulation. Because the simulation results depend on the initial conditions, initial values of $k_{1}, k_{2}$, and $k_{3}$ were determined based on a study of Shimaji et al. (1976). The initial $k_{p}$ value was 0.5 . After determining the best-fit parameters, variation of elastic moduli was examined with values near the best-fit values.

\section{Results and discussion}

\section{Cell model and elastic modulus in each direction}

Elastic moduli $(E)$ in both radial $(\mathrm{R})$ and tangential $(\mathrm{T})$ directions ( $E_{R}$ and $E_{T}$, respectively) are primarily discussed in this study because $E$ in the L direction $\left(E_{L}\right)$ depends on the ratio of cell wall dimension to transverse area and not on the transverse shape. As mentioned in the Introduction, cell types, cell wall structure, and cell layering play a role for transverse $E$. EW and LW, cell wall thicknesses, and dimensions are also important. Ray tissue will be ignored here to simplify the discussion.

These requirements are fulfilled in the model, and in Figure $1 \mathrm{a}-\mathrm{c}$ the shaded portions have load. Concerning the transverse section, parameters $k_{1}>1, k_{2} / k_{1}<1$, and $k_{3}>>1$ were considered because the cell wall is longer in $\mathrm{R}$ direction than in $\mathrm{T}$ direction for $\mathrm{EW}$, the fraction of LW is less than that of EW, and $\mathrm{LW}_{\text {thickness }}>>\mathrm{EW}_{\text {thickness }}$ in the transverse section.

Elastic modulus in the radial direction EW and LW cells are arranged in the $\mathrm{R}$ direction and have different cell wall thicknesses. In the model (Figure 1a), the cell shapes are approximated by rectangles both for EW and LW using parameters $k_{1}, k_{2}$, and $k_{3}$. Then, the length of EW and LW in $\mathrm{R}$ direction and cell wall thickness of $\mathrm{LW}$ are $k_{1} l, k_{2} l$, and $k_{3} t$, respectively: $l$ and $t$ are the cell wall length in T direction and cell wall thickness of EW, respectively.

$E_{R}$ is governed by the cell wall along the R direction, RL. Thus, by neglecting the cell wall in the $\mathrm{T}$ direction (TL), Eq. (1) is written as

$E_{R}^{e w}=(2 t / l) E_{s}^{\prime \prime}$

where $E_{R}^{e w}$ and $E_{s}^{\prime \prime}$ are the elastic moduli of EW and the cell wall in the $\mathrm{R}$ direction, respectively. In our discussion, $E_{s}^{\prime \prime}$ is also equal to the $E$ of the cell wall in the T direction. Calculation values from Tables 2 and 3 were $E_{s}^{\prime \prime}=14.14$ (GPa). Considering $\rho_{s}>>\rho^{e w}$ based on the relationship between the density of $\mathrm{EW} \rho^{\text {ew }}$ and the wood cell wall $\rho_{s}$, the term $t / l$ in Eq. (1) represents

$\left.t / l=k_{1} /\left\{2\left(1+k_{1}\right)\right\} \rho^{e w} / \rho_{s}\right)$

Thus, Eq. (1) reduces to a

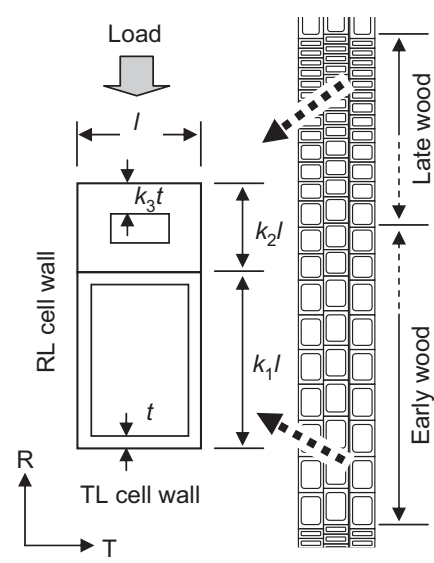

b

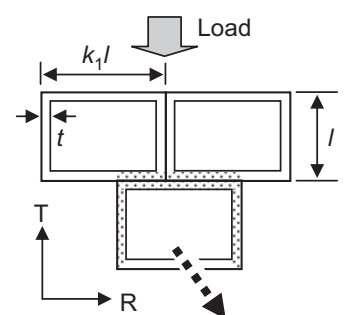

Beam in bending + pillar in $\mathrm{L}$ compressing

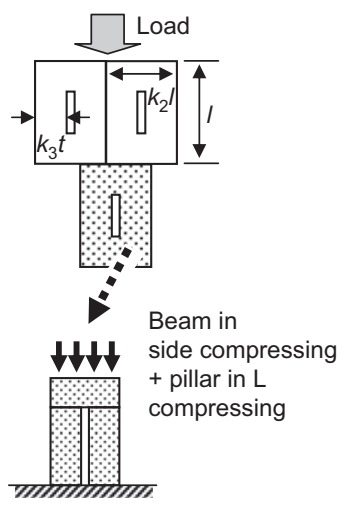

Figure 1 Cell models. (a) Symbols of cells in series representing EW and LW. (b) Model of EW under loading in the tangential direction. (c) Model of late wood under loading in the tangential direction. 
Table 1 Experimental data listed in the Wood Industry Handbook (see references) and calculated results from this study.

\begin{tabular}{|c|c|c|c|c|c|c|c|c|}
\hline & & & Measuren & & & & Calculation & \\
\hline & od species & Density $\left(\mathrm{g} \mathrm{cm}^{-3}\right)$ & $E_{L}(\mathrm{GPa})$ & $E_{R}(\mathrm{GPa})$ & $E_{T}(\mathrm{GPa})$ & $E_{L}(\mathrm{GPa})$ & $E_{R}(\mathrm{GPa})$ & $E_{T}(\mathrm{GPa})$ \\
\hline Sitka spruce & (Picea sitchensis) & 0.38 & 11.67 & 0.90 & 0.50 & 10.62 & 0.80 & 0.36 \\
\hline Sitka spruce & (Picea sitchensis) & 0.39 & 10.69 & 0.71 & 0.43 & 10.84 & 0.83 & 0.37 \\
\hline Douglas fir & (Pseudotsuga menziesii) & 0.48 & 15.69 & 1.06 & 0.78 & 12.72 & 1.02 & 0.49 \\
\hline Scots pine & (Pinus sylvestris) & 0.55 & 16.28 & 1.10 & 0.57 & 14.01 & 1.16 & 0.59 \\
\hline Douglas fir & (Pseudotsuga menziesii) & 0.59 & 16.38 & 1.30 & 0.90 & 14.69 & 1.25 & 0.66 \\
\hline Japanese fir & (Abies firma) & 0.33 & 7.36 & 0.59 & 0.29 & 9.46 & 0.70 & 0.30 \\
\hline Yezo spruce & (Picea jezoensis) & 0.39 & 10.79 & 0.83 & 0.44 & 10.84 & 0.83 & 0.37 \\
\hline Japanese red pine & (Pinus densiflora) & 0.51 & 11.77 & 1.23 & 0.64 & 13.29 & 1.08 & 0.53 \\
\hline$\underline{\text { Balsa }}$ & (Ochroma lagopus) & 0.13 & 3.73 & 0.18 & 0.06 & 4.10 & 0.28 & 0.11 \\
\hline$\underline{\text { Gibo }}$ & (unknown) & 0.14 & 1.67 & 0.29 & 0.09 & 4.40 & 0.30 & 0.11 \\
\hline Yellow poplar & (Liriodendron tulipifera) & 0.38 & 9.71 & 0.89 & 0.41 & 10.62 & 0.80 & 0.36 \\
\hline Mahogany & (Swietenia macrophylla) & 0.50 & 11.38 & 1.22 & 0.74 & 13.10 & 1.06 & 0.52 \\
\hline Sweetgum & (Liquidambar styraciflua) & 0.54 & 11.67 & 1.34 & 0.59 & 13.83 & 1.14 & 0.58 \\
\hline Birch & (Betula alleghaniensis) & 0.62 & 16.28 & 1.11 & 0.62 & 15.16 & 1.31 & 0.71 \\
\hline Yellow birch & (Betula alleghaniensis) & 0.64 & 14.32 & 1.12 & 0.72 & 15.47 & 1.35 & 0.74 \\
\hline$\underline{\text { Oak }}$ & (Quercus crispula) & 0.66 & 5.30 & 2.14 & 0.97 & 15.76 & 1.40 & 0.78 \\
\hline$\underline{B e e c h}$ & (Fagus crenata) & 0.75 & 13.73 & 2.25 & 1.14 & 16.93 & 1.59 & 0.96 \\
\hline Beech & (Fagus crenata) & 0.62 & 12.26 & 1.32 & 0.59 & 15.16 & 1.31 & 0.71 \\
\hline Birch & (Betula verrucosa) & 0.71 & 15.69 & 1.08 & 0.83 & 16.44 & 1.50 & 0.87 \\
\hline Paulownia & (Paulownia tomentosa) & 0.29 & 5.88 & 0.59 & 0.25 & 8.48 & 0.61 & 0.26 \\
\hline Japanese oak & (Quercus serrata) & 0.70 & 11.28 & 1.42 & 0.74 & 16.31 & 1.48 & 0.85 \\
\hline Zelkova & (Zelkova serrata) & 0.70 & 10.30 & 1.86 & 1.23 & 16.31 & 1.48 & 0.85 \\
\hline Locust tree & (Hymenaea courbaril) & 0.75 & 12.75 & 1.72 & 1.13 & 16.93 & 1.59 & 0.96 \\
\hline Yew & (Taxus brevifolia) & 0.83 & 16.18 & 1.86 & 0.93 & 17.77 & 1.76 & 1.15 \\
\hline Light red meranti & (Shorea spp.) & 0.51 & 11.47 & 0.97 & 0.41 & 13.29 & 1.08 & 0.53 \\
\hline Red lauan & (Shorea negrosensis) & 0.53 & 12.95 & 1.00 & 0.51 & 13.66 & 1.12 & 0.56 \\
\hline Apitong & (Dipterocarpus app.) & 0.64 & 19.61 & 1.08 & 0.54 & 15.47 & 1.35 & 0.74 \\
\hline Apitong & (Dipterocarpus app.) & 0.73 & 15.50 & 1.76 & 0.76 & 16.69 & 1.55 & 0.92 \\
\hline Phdiek & (Anisoptera spp.) & 0.70 & 17.65 & 1.55 & 0.69 & 16.31 & 1.48 & 0.85 \\
\hline Keruing & (Dipterocarpus spp.) & 0.76 & 21.87 & 1.61 & 0.77 & 17.05 & 1.61 & 0.98 \\
\hline
\end{tabular}

$E$, elastic modulus in the anatomical directions; Underline, not significant correlation between modulus and density on logarithmic scale.

$E_{R}^{e w}=k_{1} /\left(1+k_{1}\right)\left(\rho^{e w} / \rho_{s}\right) E_{s}^{\prime \prime}$

and by the same procedure to

$E_{R}^{l w}=k_{2} /\left(1+k_{2}\right)\left(\rho^{l w} / \rho_{s}\right) E_{s}^{\prime \prime}$

where $E_{R}^{l w}$ and $\rho^{l w}$ are the elastic modulus and density of LW, respectively.

The fraction of LW $\omega$ and the density ratio of LW to EW $\gamma$ are calculated from the above model. The former is represented by

$\omega=k_{2} l^{2} /\left(k_{1} l^{2}+k_{2} l^{2}\right)=k_{2} /\left(k_{1}+k_{2}\right)$

Table 2 Volume fraction and MFA in the cell wall.

\begin{tabular}{lcccc}
\hline & & \multicolumn{3}{c}{ Layers of sec. wall } \\
\cline { 3 - 5 } & $(\mathrm{I}+\mathrm{P})$ & $\mathrm{S} 1$ & $\mathrm{~S} 2$ & $\mathrm{~S} 3$ \\
\hline Volume frac. & 0.07 & 0.08 & 0.80 & 0.05 \\
MFA $^{\mathrm{a}}$ & $90^{\circ}$ & $90^{\circ}$ & $0^{\circ}$ & $90^{\circ}$ \\
\hline
\end{tabular}

${ }^{a}$ MFA: simplified hypothetical values. I, intercellular layer; P, primary wall; $\mathrm{S}$, secondary wall.
The latter is represented by

$\gamma=\rho^{l w} / \rho^{e w} \approx\left(k_{1} k_{3} / k_{2}\right)\left(1+k_{2}\right) /\left(1+k_{1}\right)$

for the approximating case that $t / l$ is small.

The elastic modulus of wood in the $\mathrm{R}$ direction is represented by

$1 / \bar{E}_{R}=\omega / E_{R}^{l w}+(1-\omega) / E_{R}^{e w}$

Substituting Eqs. (3) and (4) into Eq. (5), and integrating density $\rho=(1-\omega) \rho^{e w}+\omega \rho^{l w}$, we obtain

$$
\begin{aligned}
\bar{E}_{R}= & \left(1+k_{2} /\left(k_{1} k_{3}\right)\right)^{-1}\left(1+k_{3}\left(1+k_{2}\right) /\left(1+k_{1}\right)\right)^{-1} \\
& {\left[\left(k_{1}+k_{2}\right)^{2} /\left\{k_{1}\left(1+k_{1}\right)\right\}\right]\left(\rho / \rho_{s}\right) E_{s}^{\prime \prime} }
\end{aligned}
$$

On a logarithmic scale

$$
\begin{aligned}
\ln \left[\bar{E}_{R}\right]= & \ln [\rho]-\ln \left[\rho_{s}\right]+\ln \left[E_{s}^{/ /}\right]-\ln \left[1+k_{2} /\left(k_{1} k_{3}\right)\right] \\
& -\ln \left[1+k_{3}\left(1+k_{2}\right) /\left(1+k_{1}\right)\right]-\ln \left[\left(k_{1}+k_{2}\right)^{2} /\left\{k_{1}\left(1+k_{1}\right)\right\}\right]
\end{aligned}
$$

Ohgama and Yamada $(1971,1974)$ reported similar equations based on the law of mixtures not considering a cell wall model and derived a linear relationship between $\ln \left[\bar{E}_{R}\right]$ and $\operatorname{In}[\rho]$. 
Table 3 Volume fractions and elastic constants of wood components in each layer.

\begin{tabular}{|c|c|c|c|c|c|c|c|}
\hline & \multicolumn{4}{|c|}{ Volume fractions } & \multicolumn{3}{|c|}{ Elastic constants (GPa) } \\
\hline & $(\mathrm{I}+\mathrm{P})$ & $\mathrm{S} 1$ & S2 & S3 & $E_{x}$ & $E_{y}=E_{z}$ & $E_{x y z}$ \\
\hline Cellulose crystalline (C) & 0.13 & 0.22 & 0.27 & 0.16 & 134 & 27.2 & \\
\hline Cellulose amorphous (N) & 0.12 & 0.19 & 0.24 & 0.14 & 100 & 22.3 & \\
\hline Matrix $(\mathrm{M})$ & 0.75 & 0.59 & 0.49 & 0.70 & & & 4 \\
\hline
\end{tabular}

I, intercellular layer; $\mathrm{P}$, primary wall; $\mathrm{S}$, secondary wall. Numbers 1,2 , and 3 of S: three layers of secondary wall; $E$, directional Young's modulus; $x$, direction along polymer chain; $x$ and $y$, direction perpendicular to $x ; x y z$, isotropic.

However, $E_{s}^{/ /}$determined based on experimental results was much smaller than the theoretical value. For example, Watanabe and Norimoto (2000) calculated theoretical values between 10 and $17 \mathrm{GPa}$ in the cases of various elastic moduli of the matrix lignin plus hemicellulose. Our theoretical calculation also yielded 14.14 GPa based on Tables 2 and 3. The best-fit simulation data in R direction in Table 1 give $\ln \left[\bar{E}_{R}\right]=\ln [\rho]+0.750$, so that $E_{s}^{\prime \prime} \approx 14 \mathrm{GPa}$ is close to the theoretical result from Tables 2 and 3. These discrepancies to the data of Ohgama and Yamada $(1971,1974)$ can be probably explained by the lack of the fourth to sixth terms on the right-hand side in their version of Eq. (9).

The $E_{R}$ is represented by Eq. (9), in which the cell wall density $\rho_{s}$ is constant (1.50). Thus, dependency of $\bar{E}_{R}$ of wood species relates to the fourth to sixth terms on the right-hand side of Eq. (9), if $E_{s}^{/ /}$is constant.

Elastic modulus in the tangential direction It is difficult to derive the $E_{T}$ based on a cell model because the wood cells are not arranged in a similar way as in the R direction (Boutelje 1962). As shown in Figure 1b and c, neighboring cell walls bond in letter " $T$ " formations, so that derivation of the elastic moduli requires a different approach in EW and LW.

As shown in Figure 1b, it is assumed that loading to EW causes bending and compression of the cell wall. Under this deformation, $E_{T}^{e w}$ is according to the laws of material mechanics:

$$
\begin{aligned}
E_{T}^{e w}= & \left(1 / k_{1}\right)\left\lfloor\left\{k_{p}^{3}\left(1-k_{p}\right)^{3}\left(k_{1} l-2 t\right)^{3}\right\} /\right. \\
& \left.\left(3 E_{T 1} I_{T 1}\right)+(l-2 t) /\left(2 E_{T 2}\right)\right]^{-1}
\end{aligned}
$$

where $k_{p}$ represents the position parameter of the cell wall perpendicular to a beam cell wall, as shown at the bottom of Figure $1 \mathrm{~b} ; E_{T 1}$ and $E_{T 2}$ are the elastic moduli for bending and compression, respectively; $I_{T 1}$ is the moment of inertia in bending. $E_{T 1}$, $E_{T 2}$, and $I_{T 1}$ are calculated with values in Tables 2 and 3, which are adapted from Watanabe and Norimoto (2000). For the sake of simplicity, MFAs are supposed to be $90^{\circ}$ for I+P and S1, and $0^{\circ}$ for $\mathrm{S} 2$; I, P, and $\mathrm{S}$ represent the intracellular layer, primary wall, and secondary wall, and subscripts 1,2 , and 3 indicate layers in the secondary cell wall, respectively. After substituting the values from Tables 2 and 3 into Eq. (10), we obtain:

$E_{T}^{e w}=\left(1 / k_{1}\right)\left[C_{1} k_{p}^{3}\left(1-k_{p}\right)^{3}\left\{k_{1}(l / t)-2\right\}^{3} C_{2}(l / t-2)\right]^{-1}$

where $C_{1}=0.1492$ and $C_{2}=0.03536$ relate to the volume fraction of wood components and their elastic moduli.
There is minimal deformation of the LW beam because of its thick cell wall. As a result, both side and longitudinal compression of the cell wall will occur under loading:

$E_{T}^{l w}=\left(1 / k_{2}\right)\left[\left(1 / E_{T 1}\right)+\left(l / t-2 k_{3}\right) /\left(2 E_{T 2}\right)\right]^{-1}$

With data on Tables 2 and 3:

$E_{T}^{l w}=\left(1 / k_{2}\right)\left[C_{1}+C_{2}\left((l / t)-2 k_{3}\right)\right]^{-1}$

From the above results for EW and LW, the elastic moduli in $\mathrm{T}$ direction can be calculated, considering the fact that EW and LW are parallel to the T direction and that the fraction of LW is $\omega=k_{2} /\left(k_{1}+k_{2}\right)$. The $\bar{E}_{T}$ is represented by:

$$
\begin{aligned}
\bar{E}_{T}= & \omega E e_{T}^{e w}+(1-\omega) E_{T}^{l w} \\
= & \left\{1 /\left(k_{1}+k_{2}\right)\right\}\left[C_{1} k_{p}^{3}\left(1-k_{p}\right)^{3}\left(k_{1}(l / t)-2\right)^{3} C_{2}(l / t-2)\right]^{-1} \\
& +\left\{1 /\left(k_{1}+k_{2}\right\}\left[C_{1}+C_{2}\left(l / t-2 k_{3}\right)\right]^{-1}\right.
\end{aligned}
$$

It should be noted that the term $t / l$ in Eq. (14) is a function of $\rho$, as follows. Wood density $\rho$ is represented by $\rho=(1-\omega) \rho^{e w}+\omega \rho^{l w}$, where $\rho^{e w}$ and $\rho^{l w}$ are the densities of EW and LW, respectively. Moreover, based on the relationship between $\rho^{e w}, \rho^{l w}$, and $\rho_{s}(=1.50)$, the equation is:

$t / l=\left[\left(k_{1}+k_{2}\right) /\left[2\left\{\left(1+k_{1}\right)+\left(1+k_{2}\right) k_{3}\right\}\right]\right]\left(\rho / \rho_{s}\right)$

\section{Comparison of experimental and calculated data}

The experimental relationship between $E$ and wood density is shown on a logarithmic scale in Figure 2. The slopes of the radial and tangential lines are 1.15 and 1.41 , respectively. This result is close to that obtained for 11 wood species including softwood and hardwood species by Ohgama and Yamada (1971, 1974).

Parameters $k_{1}, k_{2}, k_{3}$, and $k_{p}$ in Eqs. (8) and (14) were confirmed to best fit both the $\mathrm{R}$ and $\mathrm{T}$ data in Table 1 at the same time. Best-fitting conditions were $k_{1}=1.81, k_{2}=0.470$, $k_{3}=6.62$, and $k_{p}=0.50$. Even when $k_{1}$ is reduced to $k_{1}=1.00$, without changing the other parameters, the fitting was good. The best-fitting values are reasonably comparable to data of the wood microstructure observed by Shimaji et al. (1976). Parameter $k_{p}=0.50$ also appears to be reasonable because the value of $k_{p}$ is probably 0.50 when the cell wall position is randomly distributed on the beam. However, $t / l$ as a function of wood density shown in Eq. (15) is smaller than the lowest 

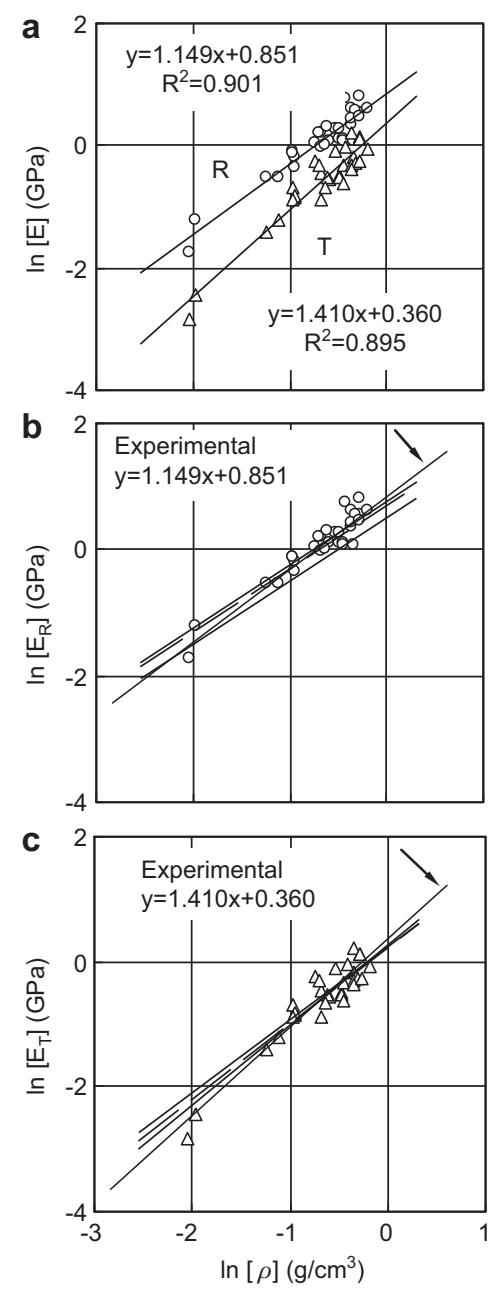

Figure 2 Elastic moduli vs. density on double logarithmic scales. (a) Data for the 30 wood species presented in Table 1. (b) Simulation results and experimental data for the elastic moduli the radial direction $\left(E_{R}\right)$ vs. density. Parameters: solid line $k_{1}=1.81, k_{2}=0.470, k_{3}=$ 6.62; long dashed line $k_{1}=1.50, k_{2}=0.400, k_{3}=6.00$; short dashed line $k_{1}=1.00, k_{2}=0.400$, and $k_{3}=0.500$. (c) Simulation results and experimental data for the elastic modulus in the tangential direction $\left(E_{T}\right)$ vs. density. Parameter as in case of (b).

data limit for some soft woods observed by Shimaji et al. (1976), as shown in Figure 3. Simulation results demonstrate that our model is satisfactory.

The $E_{L}$ was calculated with the volume fraction from the above result and $E_{s}{ }^{L}$ calculated from data in Tables 1-3. Comparisons of the calculated and experimental results are presented in Figure 4 for the R, T, and L directions. The relationship between both results forms a linear line with a slope of 1 , when excluding some wood species (which are underlined in Table 1). This finding can be considered as validation of the presented cell wall model.

\section{Coarse graining and linearity}

The question in focus is: how can the relationship between the $E$ and density be linear on a logarithmic scale although

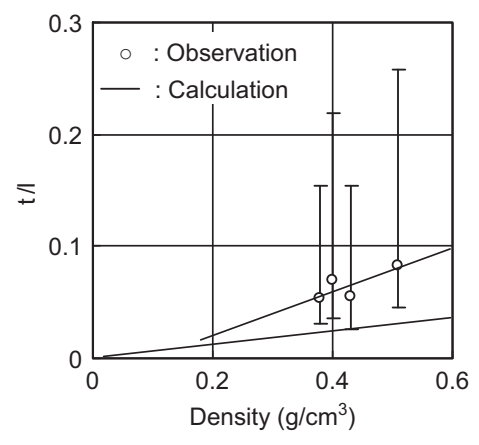

Figure 3 Relationship between the ratio of cell wall thicknesses to the TL cell wall dimension $t / l$ density of four softwood species (Japanese yew, Yezo spruce, Japanese fir, and Saghalin fir) observed by Shimaji et al. (1976). Plots: experimental results; solid line: best fitting found in the present work.

wood species have diverse and disparate macro- and microstructures? Considering the terms related to the cell wall in Eqs. (8) and (14), linearity should only appear by ignoring specific features, i.e., if a "coarse graining" can be supposed. The parameters in Eqs. (8) and (14) will be considered.

Note that the fraction of LW in the transverse section $\omega$ and the density ratio of LW to EW $\gamma$ are defined by Eqs. (5) and (6) in this study. Mayer-Wegelin (1955) and Kollmann and Coté (1968) reviewed data for $\omega$ and $\gamma$ and noted that they are similar but variable.

Mayer-Wegelin (1955) showed that the density ratio $\gamma$ is approximately 2.5 for softwood and approximately 1.5 for hardwood for 59 samples including 23 wood species. Thus, $\gamma$ can be regarded as approximately 2.0 for these wood species. As for data reviewed by Mayer-Wegelin (1955), $\rho$ vs. $\rho^{l w}$ was approximately linear. The relationship between wood density $\rho$ and the fraction of LW $\omega$ is represented by $\rho=\{(1-1 / \gamma) \omega+1 / \gamma\} \rho^{l w}$. As a result, $\omega \approx$ const. because of $\gamma=$ const. Additionally, $k_{1}>1, k_{2} / k_{1}<1$, and $k_{3}>>1$ for parameters in Figure $2 \mathrm{a}-\mathrm{c}$ are linear, as mentioned above.

These facts are important for "coarse graining" and are common for most wood species, with some exceptions. Coarse graining is an approximation obtained by neglecting

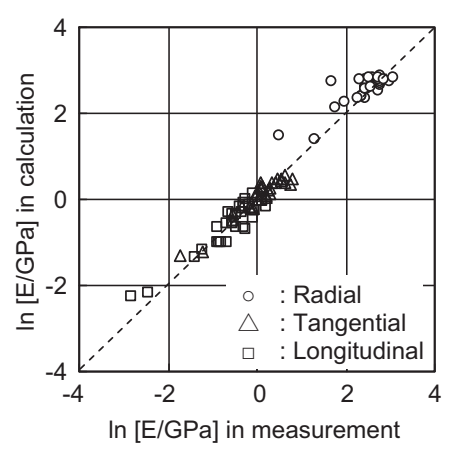

Figure 4 Comparison of the measured and calculated data for the elastic moduli in radial, tangential, and longitudinal directions for wood species presented in Table 1. 
small variations. Thus, "constant" means in this paper that values vary within a limited range.

Radial direction Equation (9) shows linearity for the R direction, if the fourth to sixth terms on the right-hand side in Eq. (9) are independent of the wood species. Simulation by Watanabe and Norimoto (2000) indicated that $E_{s}^{/ /}$is independent of the MFA, so that its value is almost constant. Thus, $E_{s}^{\prime \prime}$ and $\rho_{s}$ in Eq. (9) are constant and equal $\rho_{s}=1.50$.

From $k_{2} / k_{1}<1$ and $k_{3}>>1$, which were mentioned above, $k_{2} /\left(k_{1} k_{3}\right)<<1$. Thus, the fourth term on the right-hand side in Eq. (9) is

$\operatorname{In}\left[k_{2} /\left(k_{1} k_{3}\right)+1\right] \approx 0=$ const.

In consideration of a fifth term, the ratio $\mathrm{LW} / \mathrm{EW} \gamma$ is constant (Mayer-Wegelin, 1955) and represented by

$\gamma=\left(k_{1} k_{3} / k_{2}\right)\left(1+k_{2}\right) /\left(1+k_{1}\right)=$ const.

Here, $k_{1} / k_{2} \approx$ const. from $\omega=k_{2} /\left(k_{1}+k_{2}\right) \approx$ const., so that $k_{3}\left(1+k_{2}\right) /$ $\left(1+k_{1}\right) \approx$ const. in Eq. (17). Accordingly:

$\operatorname{In}\left[1+k_{3}\left(1+k_{2}\right) /\left(1+k_{1}\right)\right] \approx$ const.

In the sixth term, $k_{1}\left(1+k_{1}\right) /\left(k_{1}+k_{2}\right)^{2}=\left(1+1 / k_{1}\right) /\left(1+k_{2} / k_{1}\right)^{2} \approx 1$ from $k_{2} / k_{1}<1$, giving

$\operatorname{In}\left[k_{1}\left(1+k_{1}\right) /\left(k_{1}+k_{2}\right)^{2}\right]=0 \approx$ const.

From Eqs. (16), (18), and (19), the fourth to sixth terms can approximately be regarded as constant. Finally:

$\ln \left[\bar{E}_{R}\right]=\ln [\rho]-\ln \left[\rho_{s}\right]+\ln \left[E_{s}\right]+$ const.

Equation (20) is independent of the wood species because of the constants $\rho_{s}$ and $E_{s}^{\prime \prime}$. The above discussion shows that the plots of $E$ vs. density are linear on a logarithmic scale, when $\gamma$ and $\omega$ are constant (within a limited region) regardless of wood species. These conditions approximately hold for wood species presented in the literature (Mayer-Wegelin 1955; Kollmann and Coté 1968; Shimaji et al. 1976).

Tangential direction For the $\mathrm{T}$ direction, linearity between the $E$ and density cannot be confirmed directly with Eqs. (14) and (15). However, the linearity can be approximated by considering the greater contribution of LW than that of EW.

As mentioned above, $k_{p}=0.50$ is also reasonable because the value of $k_{p}$ is probably 0.50 when the position of cell wall is randomly distributed on the beam. Since the first and second terms on the right-hand side in Eq. (14) become approximately $72(t / l)^{3}$ and $28(t / l)$, respectively, using values of $k_{p}=$ 0.50 and $C_{1}$, Eq. (14) is approximated by the second term under $(t / l)<<1$. Thus,

$\bar{E}_{T} \approx 1 /\left\{C_{2}\left(k_{1}+k_{2}\right)\right\}(t / l)$

In combination with Eq. (15), this reduces to $\ln \left[\bar{E}_{T}\right] \approx \ln [\rho]-\ln \left[\rho_{s}\right]-\ln \left[2 C_{2}\right]-\ln \left[\left(1+k_{1}\right)+\left(1+k_{2}\right) k_{3}\right]$

The fourth term on the right-hand side in Eq. (22) is constant, if $k_{1}$ is constant because $\left(1+k_{1}\right)+\left(1+k_{2}\right) k_{3}=\left(1+k_{1}\right)$ $\left\{1+\left(1+k_{2}\right) k_{3} /\left(1+k_{1}\right)\right\}$ and then $\left(1+k_{2}\right) k_{3} /\left(1+k_{1}\right) \approx$ const. under $k_{1}=$ const., as discussed above. Thus, the relationship between $E$ and density is linear on a logarithmic scale. In this situation, the slope is unity. This seems to be a proof that Eq. (14) is linear regardless of wood species.

Longitudinal direction Linearity in the $\mathrm{L}$ direction is easily shown because the $E$ depends merely on the fraction of wood cells (wood substance) in the transverse area; that is, $\bar{E}_{L}=\theta_{s} E_{s}^{\prime \prime}$, where $\theta_{s}$ is the volume fraction of wood substance and is proportional to density. Accordingly, their relationships are linear. The results calculated with these parameters are listed in Table 1.

\section{Conclusions}

The elastic modulus $E$ in the radial and tangential directions $\left(E_{R}\right.$ and $E_{T}$ ) was formulated based on a cell wall model considering a high-order structure of wood. Parameters in the equations were confirmed by comparison to best-fit experimental data, which were $k_{1}=1.81, k_{2}=0.470, k_{3}=6.62$, and $k_{p}=0.50$. These values are reasonable compared to the microstructure of wood reported so far. The simulation validates the model and the formulations.

The linearity in each direction between the data of $E$ and density on a logarithmic scale arises from the common wood structures between species. As a result, the intercept in the derived equations is constant regardless of the wood species; in other words, they are "coarse-grained". The common structures of species are elastic modulus of the cell wall, the fraction of LW in the transverse section, the density ratio of LW to EW, and the ratio of radial to tangential length of the cells. These factors allow to neglect variation within a limited region. In other words again, "coarse graining" will be possible.

\section{References}

Boutelje, J.B. (1962) The relationship of structure to transverse anisotropy in wood with reference to shrinkage and elasticity, Holzforschung 16:33-46.

Chou, P.C., Carleone, J. (1972) Elastic constant of layered media. J Compos. Mater. 6:81-93.

Fengel, D., Wegener, G. Wood-Chemistry, Ultrastructure, Reactions. De Gruyter, Berlin, 1989, pp. 613.

For. and For. Prod. Res. Inst. Wood Industry Handbook. Maruzen Co Ltd., Tokyo, 1982, pp. 130-131.

Gibson, L.J., Ashby, M.F. Cellular Solids. University Press, Cambridge, 1999, pp. 93-106.

Hofstetter, K., Hellmich, C., Eberhardsteiner, J. (2005) Development and experimental validation of a continuum micromechanics model for the elasticity of wood. Eur. J. Mech. A-Solid 24:1030-1053. 
Hofstetter, K., Hellmich, C., Eberhardsteiner, J., Mang, H.A. (2008) Micromechanical estimates for elastic limit states in wood materials, revealing nanostructure failure mechanism. Mech. Adv. Mater. Struc. 15:474-484.

Houwink, R. Elasticity, Plasticity and Structure of Matter. The University Press, Cambridge, 1954.

Kanaya, N., Yamada, T. (1964) The relation between the elastic modulus and the porosity of wood. Wood Res. 33:47-55.

Kollmann, F.F.P., Coté, Jr, W.A. Principles of Wood Science and Technology (I). Springer-Verlag, Berlin/Heidelberg/New York, 1968, pp. 173-179.

Maekawa, T., Fujita, M., Sasaki, H. (1993) Characterization of cell arrangement by polar coordinate analysis of power spectrum pattern. Zairyo (J. Soc. Mater. Sci Jpn.) 42:126-131.

Mayer-Wegelin, H. Das Holz als Rohstoff, Carl Hanser Verlag, München, 1955, pp. 404-407.

Nakano, T. (2003) Effects of cell structure on water sorption for wood. Holzforschung 57:213-218.

Nakano, T. (2008) Analysis of cell wall swelling on the basis of a cylindrical model. Holzforschung 62:352-356.

Ohgama, T., Yamada, T. (1971) Porous structure of wood and its relaxation modulus (in Japanese). Zairyo 20:1194-1200.

Ohgama, T., Yamada, T. (1974) Elastic modulus of porous material (in Japanese). Mokuzai Gakkaishi 20:166-171.

Price, A.T. (1929) A mechanical discussion on the structure of wood in relation to its elastic properties. Trans. Farad. Soc. 228:1-62.

Salmén, L. (2004) Micromechanical understanding of the cell-wall structure. C.R. Biologies 327:873-880.
Salmén, L., Burgert, I. (2009) Cell wall features with regard to mechanical performance. A review. Holzforschung 63:121-129.

Shimaji, K., Sudo, S., Harada, H. Wood Structure (in Japanese), Morikita-Shuppan, Tokyo, 1976.

Stevanic, J.S., Salmén, L. (2009) Orientation of the wood polymers in the cell wall of spruce wood fibres. Holzforschung 63:497-503.

Taguchi, S., Murata, K., Nakano, T. (2010) Observation of cell shapes in wood cross-sections during water adsorption by confocal laserscanning microscope (CLSM). Holzforschung 64:627-631.

Taguchi, S., Murata, K., Nakamura, M., Nakano, T. (2011) Scale effect in the anisotropic deformation change of tracheid cells during water adsorption. Holzforschung 65:253-256.

Tang, R.C., Hsu, N.N. (1973) Analysis of the relationship between microstructure and elastic properties of the cell wall. Wood Fiber Sci. 5:139-151.

Watanabe, U., Norimoto, M. (2000) Three dimensional analysis of elastic constants of the wood cell wall. Wood Res. 87:1-7.

Watanabe, U., Norimoto, M., Ohgama, T., Fujita, M. (1999) Tangential Young's modulus of coniferous earlywood investigated using cell models. Holzforschung 53:209-214.

Watanabe, U., Fujita, M., Norimoto, M. (2002) Transverse shrinkage of coniferous wood cells examined using replica method and power spectrum analysis. Holzforschung 56:1-6.

Yamamoto, H. (2004) Role of the gelatinous layer on the origin of the physical properties of the tension wood. J. Wood Sci. 50:197-208.

Received January 15, 2012. Accepted June 11, 2012. Previously published online August 2, 2012. 
Copyright of Holzforschung: International Journal of the Biology, Chemistry, Physics, \& Technology of Wood is the property of De Gruyter and its content may not be copied or emailed to multiple sites or posted to a listserv without the copyright holder's express written permission. However, users may print, download, or email articles for individual use. 